Technological University Dublin ARROW@TU Dublin

\title{
Polyesters with main and side chain phosphoesters as structural motives for biocompatible electrospun fibres
}

André E. Polloni

Royal College of Surgeons in Ireland

Viviane Chiaradia

Royal College of Surgeons in Ireland

Ronaldo José F.C. do Amaral

Royal College of Surgeons

See next page for additional authors

Follow this and additional works at: https://arrow.tudublin.ie/ittsciart

Part of the Materials Chemistry Commons, Other Chemistry Commons, and the Polymer Chemistry Commons

\section{Recommended Citation}

Polloni AE, Chiaradia V, do Amaral RJFC, Kearney C, Gorey B, de Oliveira D, de Oliveira JV, de Araújo PHH, Sayer C, Heise A. Polyesters with main and side chain phosphoesters as structural motives for biocompatible electrospun fibres. Polymer Chemistry. 2020;12:2157-2165

This Article is brought to you for free and open access by the School of Science and Computing at ARROW@TU Dublin. It has been accepted for inclusion in Articles by an authorized administrator of ARROW@TU Dublin. For more information, please contact arrow.admin@tudublin.ie, aisling.coyne@tudublin.ie, gerard.connolly@tudublin.ie. 


\section{Authors}

André E. Polloni, Viviane Chiaradia, Ronaldo José F.C. do Amaral, Cathal Kearney, Brian Gorey, Débora de Oliveira, José V. de Oliveira, Pedro H.H. de Araújo, Claudia Sayer, and Andreas Heise 


\title{
Polyesters with main and side chain phosphoesters as structural motives for biocompatible electrospun fibres
}

Received 00th January 20xx, Accepted 00th January 20xx DOI: $10.1039 / \times 0 \times x 00000 x$

\author{
André E. Polloni, $+^{a, b}$ Viviane Chiaradia, ${ }^{a, b}$ Ronaldo José F. C. do Amaral, ${ }^{c, d}$ Cathal Kearney, ${ }^{c}$ Brian \\ Gorey, ${ }^{\text {e }}$ Débora de Oliveira, ${ }^{\mathrm{b}}$ José V. de Oliveira, ${ }^{\mathrm{b}}$ Pedro H. H. de Araújo, ${ }^{\mathrm{b}}$ Claudia Sayer, ${ }^{\mathrm{b}}$ Andreas \\ Heise*a,d,f
}

\begin{abstract}
Phosphoester containing polymers are promising materials in biomedical applications due to their biocompatibility and biodegradability. Utilising thiol-ene chemistry, the synthesis of two novel structural polymer motives combining polyesters and phophoester groups was explored. The first polymer was obtained by coupling ene-functional poly(thioetherphosphoester) with thiol functional poly(pentadecalactone). While the coupling reaction was successful, yields remained low presumably due to inadequate endgroup stoichiometry. The second polymer comprised phosphoester side groups conjugated to unsaturated poly(globalide). Double bond conversions up to $84 \%$ were achieved depending of the type of phosphoester thiol and relative reactant ratios. The resulting polymers transitioned from solid semicrystaline to liquid amorphous with increasing degree of phosphoester conjugation. Electrospun fibres from polymers with $14 \%$ phosphoester conjugation allowed attachment and survival of human dermal fibroblasts, indicating their biocompatibility. These polymers represent a new class of easily accessible biocompatible polyester-phosphoester hybrid materials as potential building blocks for tunable biomaterials.
\end{abstract}

polyesters has established itself as a widely applied processing

\section{Introduction}

The design of biopolymers with enhanced biological activity is central to the development of next generation biomaterials, for example in the areas of tissue regeneration. ${ }^{1-5}$ Direct incorporation of functionalities capable of facilitating cell proliferation into defined positions of the polymer backbone is an attractive approach that could provide advantages over commonly applied physical blending methods. 6,7 However, this approach requires the development of novel polymeric materials, which have to meet a set of general requirements such as non-toxicity, biodegradability (if desired) as well as other requirements dictated by the specific application. In addition, processability into applicable formats to enable integration into biomedical devices is essential. To that end, electrospinning of resorbable polymers such as aliphatic

\footnotetext{
a. Department of Chemistry, Royal College of Surgeons in Ireland, 123 St. Stephens Green, Dublin 2, Ireland.

b. Department of Chemical Engineering and Food Engineering, Federal University of Santa Catarina (UFSC), Florianópolis, SC 88040-900, Brazil.

c. Kearney Lab \& Tissue Engineering Research Group, Anatomy Department, Royal College of Surgeons in Ireland, 123 St. Stephens Green, Dublin 2, Ireland.

d. Science Foundation Ireland Centre for Research in Medical Devices (CURAM).

e. FOCAS Research Institute, Dublin Institute of Technology, Kevin Street, Dublin 8, Ireland.

f. Science Foundation Ireland Centre for Advanced Materials and Bioengineering Research (AMBER).

† These authors contributed equally to this work. Current address: A.E.P.: Center for Study on Colloidal Systems (NUESC)/Institute of Technology and Research (ITP) Tiradentes University (UNIT), Aracaju-SE, 49032-490, Brazil. V.C.: Department of Chemistry, University of Birmingham, Birmingham, United Kingdom B15 2TT.

Electronic Supplementary Information (ESI) available: Additional experimental procedures, NMR, SEC and DSC data. See DOI: 10.1039/x0xx00000x
} technique due to the ability to form high porosity scaffolds with micron to sub-nanoscale fibres similar to the natural extracellular matrix (ECM). .-13 $^{-1}$

Lately, poly(phosphoester)s received great attention as highly biodegradable and biocompatible polymers. ${ }^{14-18}$ The chemical versatility of phosphates allowed the synthesis of materials with complex structures and the pentavalence of the phosphorus atom enables the conjugation of functional groups. ${ }^{19}$ The potential of polymers containing phosphate and phosphonate groups for regenerative medicine and specifically bone regeneration was recently highlighted by Mikos. ${ }^{20}$ The marriage of phosphoesters or poly(phosphoester)s with other polymers is particularly attractive for the design of novel biopolymers as the specific properties of both building blocks can be combined in one material. Especially the combination of poly(phosphoester) blocks with aliphatic polyesters represents attractive structural targets due to the biocompatibility and degradability of both blocks. Poly(phosphoester) block copolymers are accessible through chain extension from macroinitiators by ring-opening polymerisation of ethyl ethylene phosphate derivatives. For example, di and triblock copolymers comprising poly(caprolactone) (PCL) or poly(lactide)s and poly(phosphoester) derivatives have been disclosed by several authors. ${ }^{21-27}$ Commonly, the controlled ring-opening polymerisation of the lactone or lactide is performed first followed by chain extension with ethyl ethylene phosphate. For most of these amphiphilic block copolymers the self-assembly into micellar structures and the loading with dyes or model drugs was studied. ${ }^{28,29}$ 
To the best of our knowledge, polyesters with individual phosphoester groups in the main or side-chain have not been reported to date. Presumably, this is due to the synthetic challenge as common aliphatic polyester such as PCL and PLA do not offer convenient functional anchor points for the attachment of phosphoesters. We hypothesise that such structures could be of potential interest as they do not impart amphiphilicity as observed for block structures thus avoiding self-assembly or phase separation upon processing. Here we report for the first time two synthetic approaches for the design of polyesters with single main and side chain phosphoesters utilising thiol-ene chemistry and poly(macrolactone)s. We further demonstrate the electrospinning of these materials into biocompatible fibres, therefore highlighting the potential of this new class of materials as strong candidates for biomedical applications.

\section{Experimental}

\section{Materials}

All reactants were purchased from Sigma-Aldrich and used a received unless otherwise noted. The monomers $\omega$ pentadecalactone and globalide (97\%) were purchased from Sigma-Aldrich and Symrise, respectively, and dried under vacuum at $70^{\circ} \mathrm{C}$ for $24 \mathrm{~h}$ prior to use. Immobilized lipase $B$ from Candida antarctica (Novozym 435) was purchased from Novozymes S/A and dried under vacuum at $50{ }^{\circ} \mathrm{C}$ for 24 h. $10-$ Undecen-1-ol, 6-mercapto-1-hexanol were dried under vacuum at $50{ }^{\circ} \mathrm{C}$ for $24 \mathrm{~h}$ before use. Phenyl dichlorophosphate, diethyl chlorophosphate and diphenyl 6-mercapto-1-hexyl phosphate were dried over molecular sieves. Pyridine was distilled from calcium hydride under inert conditions. Azobisisobutyronitrile (AIBN, Fluorechem) was recrystallised before use. Poly $(\omega-$ pentadecalactone) (PPDL) with one thiol end group, ${ }^{30}$ phenyl di(undec-10-en-1-yl) phosphate, ${ }^{31}$ and poly(globalide) $(P G I)^{32}$ were synthesised as previously reported in literature (see ESI for methodology).

\section{Synthesis of poly(thioether-phosphoester)}

Phenyl di(undec-10-en-1-yl) phosphate $(0.25 \mathrm{~g} ; 0.525 \mathrm{mmol})$ was polymerised with 1,5-pentanedithiol $(70 \mu \mathrm{L}, 0.525 \mathrm{mmol})$ in the presence of the photoinitiator DMPA. Reactions were performed in chloroform and the samples were exposed to UV light from 5 to $30 \mathrm{~min}$ at room temperature. Subsequently, the samples were dissolved in dichloromethane and precipitated in ice-cold methanol. The precipitated polymer was filtered and dried under vacuum. ${ }^{1} \mathrm{H}-\mathrm{NMR}\left(400 \mathrm{MHz}, \mathrm{CDCl}_{3}\right): \delta(\mathrm{ppm})=7.38$ - $7.30\left(\mathrm{t}, \mathrm{C}_{6} \mathrm{H}_{5} \mathrm{O}\right), 7.22$ - $7.19\left(\mathrm{~d}, \mathrm{C}_{6} \mathrm{H}_{5} \mathrm{O}\right), 7.18$ - $7.14\left(\mathrm{t}, \mathrm{C}_{6} \mathrm{H}_{5} \mathrm{O}\right)$, 4.19 - $4.09\left(\mathrm{~m}, \mathrm{CH}_{2} \mathrm{O}\right), 2.71$ - $2.66\left(\mathrm{t}, \mathrm{CH}_{2}(\mathrm{HC}=\mathrm{C})\right), 2.58$ - $2.48(\mathrm{~m}$, $\left.\mathrm{CH}_{2} \mathrm{~S}\right)$.

\section{Synthesis of poly ( $\omega$-pentadecalactone- $b$-thioether-phosphoester)}

In a typical procedure, poly(thioether-phosphoester) was conjugated with the thiol-functionalised poly $(\omega$ pentadecalactone) in the presence of photoinitiator DMPA to generate the block copolymer poly $(\omega$-pentadecalactone-b- thioether-phosphoester), poly( $\omega$-PDL-b-TEPE). As a representative example, thiol-functionalised poly $(\omega$ pentadecalactone) $(110 \mathrm{mg}, 0.025 \mathrm{mmol})$ and poly(thioetherphosphoester) $(720 \mathrm{mg}, 0.05 \mathrm{mmol}$ ) were placed in a closed vial with DMPA ( $5 \mathrm{wt} . \%$ in relation to diene) and $2 \mathrm{~mL}$ of chloroform. The vial was then kept at room temperature under UV light (200 $\mathrm{W} \mathrm{cm}{ }^{-1}, \lambda=365 \mathrm{~nm}$ for $5 \mathrm{~min}$ ). Then, the material was dissolved in dichloromethane, precipitated in ice-cold methanol, filtered and dried under vacuum. After reaching constant mass, the material was characterized by SEC, ${ }^{1} \mathrm{H}-\mathrm{NMR}$ and DSC. ${ }^{1} \mathrm{H}-\mathrm{NMR}$ $\left(400 \mathrm{MHz}, \mathrm{CDCl}_{3}\right): \delta(\mathrm{ppm})=7.38-7.30\left(\mathrm{t}, \mathrm{C}_{6} \mathrm{H}_{5} \mathrm{O}\right), 7.22-7.19(\mathrm{~d}$, $\left.\mathrm{C}_{6} \mathrm{H}_{5} \mathrm{O}\right), 7.18$ - $7.14\left(\mathrm{t}, \mathrm{C}_{6} \mathrm{H}_{5} \mathrm{O}\right), 4.19-4.09\left(\mathrm{~m}, \mathrm{CH}_{2} \mathrm{O}\right), 2.58-2.48$ (m, $\left.\mathrm{CH}_{2} \mathrm{~S}\right), 2.31-2.22\left(\mathrm{t}, \mathrm{CH}_{2} \mathrm{O}\right)$.

\section{Synthesis of thiols containing phosphoesters}

A dried $250 \mathrm{~mL}$ Schlenk flask equipped with a dropping funnel was purged with argon. Then, a toluene solution of diethyl chlorophosphate $(14.5 \mathrm{~mL} ; 0.1 \mathrm{~mol})$ - for syntheses 1 (TF1) and a toluene solution of diphenyl phosphoryl chloride ( $20.7 \mathrm{~mL} ; 0.1$ mol) - for synthesis 2 (TF2) - was added to the flask and cooled to $0^{\circ} \mathrm{C}$ in an ice bath. After reaching the specified temperature, pyridine $(8 \mathrm{~mL}$; $0.1 \mathrm{~mol}), 6$-mercapto-1-hexanol $(13.7 \mathrm{~mL} ; 0.1$ $\mathrm{mol}$ ) and toluene $(22 \mathrm{~mL}$ ) were slowly dropped $(30 \mathrm{~min})$ into the solution containing the respective phosphate. After the addition was completed, the reaction was stirred overnight at room temperature. The solution was filtered, washed with hydrochloric acid and dried over magnesium sulphate. The toluene was removed under reduced pressure and the product was purified by silica gel column using hexane:ethyl acetate (70:30). TF1 (diethyl 6-mercapto-1-hexyl phosphate): Yield: 72\%. ${ }^{1} \mathrm{H}-\mathrm{NMR}\left(400 \mathrm{MHz}, \mathrm{CDCl}_{3}\right): \delta(\mathrm{ppm})=4.08-3.92(\mathrm{~m}, 6 \mathrm{H},-$ $\left.\mathrm{CH}_{2} \mathrm{O}\right), 2.49-2.40\left(\mathrm{~m}, 2 \mathrm{H},-\mathrm{CH}_{2} \mathrm{~S}\right), 1.65-1.50(\mathrm{~m}, 8 \mathrm{H},-\mathrm{CH} 2), 1.55-$ $1.50(\mathrm{t}, 1 \mathrm{H},-\mathrm{SH}), 1.30-1.25\left(\mathrm{t}, 6 \mathrm{H},-\mathrm{CH}_{3}\right)$. TF2 (diphenyl 6mercapto-1-hexyl phosphate): Yield: $60 \% .{ }^{1} \mathrm{H}-\mathrm{NMR}(400 \mathrm{MHz}$, $\left.\mathrm{CDCl}_{3}\right): \delta(\mathrm{ppm})=7.27(\mathrm{t}, 4 \mathrm{H}), 7.19(\mathrm{~d}, 4 \mathrm{H}), 7.14(\mathrm{t}, 2 \mathrm{H}), 4.21-$ $4.12\left(\mathrm{~m}, 2 \mathrm{H},-\mathrm{CH}_{2} \mathrm{O}\right), 2.45-2.37\left(\mathrm{~m}, 2 \mathrm{H},-\mathrm{CH}_{2} \mathrm{~S}\right), 1.68-1.58(\mathrm{~m}, 8 \mathrm{H}$, $-\mathrm{CH} 2), 1.54-1.44(\mathrm{t}, 1 \mathrm{H},-\mathrm{SH})$.

\section{Post-polymerisation modification of poly(globalide) via thiol-ene chemistry}

For each thiol-phosphoester/polyglobalide combination, thiol:ene molar ratios of $0.5: 1,1: 1$ and $2: 1$ were tested for varying AIBN concentrations of 1 and 5 mol\% related to thiol. As a representative example, $\mathrm{PGI}(300 \mathrm{mg}, 1.2 \mathrm{mmol}$ ) and the respective thiol $(648 \mathrm{mg}, 2.4 \mathrm{mmol}$ - for TF2:ene of 1:2) were placed in a vial until complete solubilisation in THF. Then, AIBN (19.7 $\mathrm{mg} ; 0.12 \mathrm{mmol}$ - for $5 \mathrm{~mol} \%$ of AIBN in relation to thiol) was added and the mixture was stirred for $8 \mathrm{~h}$ at $80^{\circ} \mathrm{C}$. Subsequently, samples were dialysed against ethanol to remove unreacted thiol using a $10 \mathrm{kDa}$ MWCO membrane.

\section{Electrospinning procedure}

Fibres in a micrometric range were prepared using a Spraybase electrospinning machine with a stationary collector. The conditions for the electrospinning were adapted from literature for both block copolymer and polyester with phosphoester side groups. ${ }^{32,33}$ In all tests, the procedure was conducted at room 
temperature and a relative humidity of 40 to $50 \%$. To prepare the spinning solution of poly( $\omega$-PDL- $b$-TEPE), the block copolymer was mixed with poly( $\omega$-pentadecalactone) homopolymer in a mass ratio of $1: 1$ and the concentration of polymeric solutions ranged from 10 to $30 \mathrm{wt} . \%$ relative to the solvent mixture. In addition, the fibres were obtained when the voltage, distance from tip to collector and flow rate were set at $12 \mathrm{kV}, 10 \mathrm{~cm}$ and $50 \mu \mathrm{L} \mathrm{min} \mathrm{m}^{-1}$, respectively. Fibres of nonmodified and modified poly(globalide) were prepared at a polymer concentration of $30 \mathrm{wt} . \%$ in DCM. Flow rate $(100 \mu \mathrm{L}$ $\left.\mathrm{min}^{-1}\right)$ and distance from tip to collector $(15 \mathrm{~cm})$ were kept constant and the voltage was varied between 8 and $12 \mathrm{kV}$. For all polymers, the electrospun mats were collected on aluminium foil for SEM analysis and on Teflon for biocompatibility tests.

\section{Biocompatibility assays}

Human dermal fibroblasts (Detroit 551 - ATCC ${ }^{\circledR}$ CCL-110 $10^{\mathrm{TM}}$ ) were selected to evaluate biocompatibility of the synthesised materials. For all polymers, the electrospun mats were cut into $8 \mathrm{~mm}$ disks, sterilized with $70 \%$ ethanol and washed with phosphate saline buffer - PBS. The fibres were incubated in regular growth medium - low glucose Dulbecco's modified Eagles's medium (DMEM) supplemented with $10 \%$ fetal bovine serum (FBS; Hyclone) and 1\% penicillin/streptomycin (SigmaAldrich, Ireland) - for $30 \mathrm{~min}$ in humidified atmosphere with $5 \%$ $\mathrm{CO}_{2}$ at $37^{\circ} \mathrm{C}$ prior to cell seeding. After incubation period, 2000 cells per sample were seeded on one side of each sample $(n=3)$. The seeded fibres were kept in regular growth medium for up to 7 days, when cell metabolic activity was measured with AlamarBlue ${ }^{\circledR}$ reagent (Invitrogen). Fluorescence intensity was read on a plate spectrophotometer with excitation at $560 \mathrm{~nm}$ and emission at $590 \mathrm{~nm}$. Obtained values were normalised to PGI results, so that $\mathrm{PGI}$ average was of 1.0. Statistical significance was evaluated by unpaired two-tailed t test. For a qualitative analysis of cell viability, seeded samples cultured for 7 days were stained with $4 \mathrm{mM}$ calcein-AM (green = live) and 2 $\mathrm{mM}$ ethidium homidimer-1 ( red = dead) in PBS for $15 \mathrm{~min}$ at 37 ${ }^{\circ} \mathrm{C}$, protected from light (Live/dead viability/cytotoxicity assay, Invitrogen). The samples were then imaged in a confocal microscope at excitation and wavelengths of 515 and $615 \mathrm{~nm}$, respectively.

\section{Methods}

${ }^{1} \mathrm{H}-\mathrm{NMR}$ spectra were recorded using a Bruker spectrometer at $400 \mathrm{MHz}$ in $\mathrm{CDCl}_{3}$. Chemical shifts were reported in parts per million (ppm) from $0.00 \mathrm{ppm}$ using tetramethylsilane (TMS) $0.03 \%(\mathrm{v} / \mathrm{v})(\delta=0.00)$ as internal standard. Thermal analysis was conducted on a TA Instruments Q200 DSC, using approximately $9.0 \mathrm{mg}$ of dried purified polymer. Temperature profiles from $10^{\circ} \mathrm{C}$ to $130^{\circ} \mathrm{C}$ with heating and cooling rate of $10^{\circ} \mathrm{C} \mathrm{min}-1$ were applied under nitrogen atmosphere. The melting temperatures were determined by the second heating. Size exclusion chromatography (SEC) was performed on an Agilent 1200 series instrument with $\mathrm{dRI}$ detection. All measurements were carried out using a Polymer Laboratories Gel $5 \mu \mathrm{m}$ Mixed-C 300 x 7.5 $\mathrm{mm}$ column at $40^{\circ} \mathrm{C}$ using chloroform as eluent at a flow rate of $1 \mathrm{~mL} / \mathrm{min}$. Molecular weights were determined against polystyrene standards (from $550 \mathrm{~g} \mathrm{~mol}^{-1}$ to $1.568 \times 10^{6} \mathrm{~g} \mathrm{~mol}^{-1}$ ). Fibres morphology was confirmed by scanning electron microscopy (SEM) with a Hitachi SU 6600 Fe-SEM instrument (Hitachi High Technologies Europe GMBH Whitebrook Park Lower Cookham Road Maindenhead SL6 8YA UK). Samples were placed on conductive carbon stubs and coated with Pt/Pd using a Cressington HR sputter coater (Cressington Scientific Instruments Ltd. 4 Chalk Hill Watford WD19 4BX, England UK) giving a coating of $5 \mathrm{~nm}$. An accelerating voltage of $2 \mathrm{kV}$, working distance of $10 \mathrm{~mm}$, condenser lens of 21.0 and current of $20 \mu \mathrm{A}$ were used for all samples.

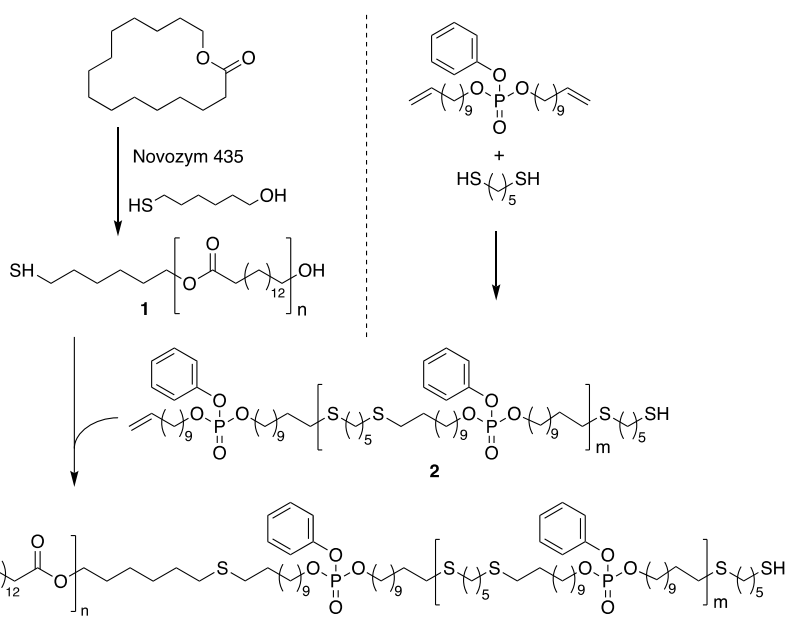

Scheme 1 Synthesis of block copolymers with phosphoesters in the main chain

\section{Results and discussion}

\section{Block copolymers with phosphoesters in the main chain}

We first targeted a block copolymer with $\operatorname{poly}(\omega$ pentadecalactone) (PPDL) as the polyester block and a thioether-phosphoester block as depicted in Scheme 1. It involved the synthesis of a thiol-ene-functional poly $(\omega$ pentadecalactone) (PPDL) $\mathbf{1}$ as well as a telechelic enefunctional poly(thioether-phosphoester) $2,^{34}$ followed by thiolene coupling of both blocks to yield the block copolymer $\mathbf{3}$. The thiol functional PPDL 1 was obtained by Candida antarctica Lipase B (CALB, Novozym 435) catalysed ring-opening polymerisation of pendadecalactone $(\mathrm{PDL})$ in the presence of 6mercapto-1-hexanol. ${ }^{30}$ Size Exclusion Chromatography (SEC) confirmed a number average molecular weight $\left(M_{n}\right)$ of $4300 \mathrm{~g}$ $\mathrm{mol}^{-1}(\theta=2.1)$ for this polymer (Figure 1$) .{ }^{1} \mathrm{H}-\mathrm{NMR}$ analysis revealed that $86 \%$ of the PPDL chains were thiol end-capped, quantified from the ratio of integrated peak signals at $3.65 \mathrm{ppm}$ of the $-\mathrm{CH}_{2} \mathrm{OH}$ endgroups ( $c^{\prime}$ in Figure $\mathrm{S} 1, \mathrm{ESI}$ ) to that of the $\mathrm{CH}_{2}$-SH signal at $2.52 \mathrm{ppm}$ (a in Figure S1, ESI). 


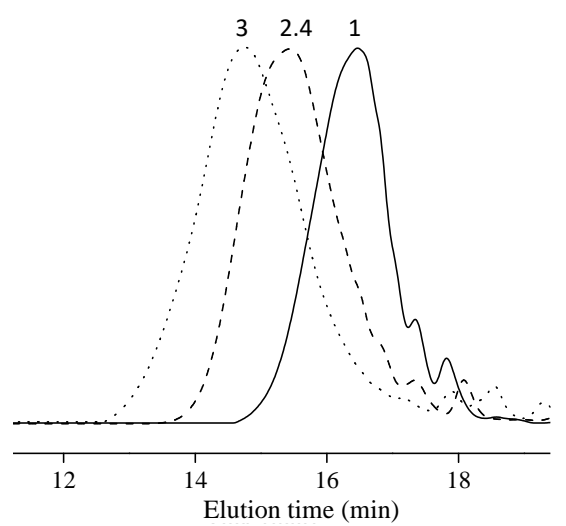

Fig. 1 Normalised SEC traces of polymers 1, 2.4 and $\mathbf{3}$ (Scheme 1, Table 1)

The thioether-phosphoester block 2 was synthesized from a phosphate diene, phenyl-di(undec-10-en-1-yl) phosphate $\left({ }^{1} \mathrm{H}\right.$ NMR see Figure S2, ESI), and a commercial 1,5-pentanedithiol at a 1:1 ratio via a thiol-ene addition reactions (Scheme 1). Using the UV-initiator 2,2-dimethoxy-2-phenylacetophenone (DMPA) as the radical source, number average molecular weights $\left(M_{n}\right)$ up to $17200 \mathrm{~g} \mathrm{~mol}^{-1}$ were reproducibly obtained with a monomodal distribution at $\oplus<2.4$ (Table 1, Figure 1). Although ${ }^{1} \mathrm{H}-\mathrm{NMR}$ analysis confirmed the equimolar ratio of the two monomers in the produced polymers, the identification of the end-groups proved challenging. While the methylene group adjacent to the thiol endgroup is undistinguishable from the methylene groups in the thioethers, the vinyl endgroup proton signals are expected between 5 and $6 \mathrm{ppm}$ but those were not detectable (Figure S3, ESI). As the presence of the latter is crucial for the attachment of the thiol-functional PPDL 1, a control experiment was carried out with an excess of the phosphate diene (1:0.75 diene to dithiol). As expected, low molecular weight oligomers were obtained in this step growth process, which allowed the clear assignment of the vinyl protons in the ${ }^{1} \mathrm{H}-\mathrm{NMR}$ spectrum (Figure S4, ESI). Although this highlights that the synthetic approach is suitable to obtain the desired end-functional polymers, it might suggest that the relative concentration of vinyl protons in the higher molecular weight samples could be too low for detection. However, the possibility of those endgroups being absent or the formation of polymers with identical endgroups cannot be excluded from these experiments. Keeping this in mind, the conjugation of $\mathbf{2 . 4}$ (Table 1) with 1 was attempted using DMPA under the notion that a successful reaction can only be realised if vinyl endgroups are indeed present. After purification to remove unconjugated 2.4, SEC analysis revealed a shift of the product trace $\mathbf{3}$ to a higher molecular weight (Figure 1) corresponding to an $M_{n}$ of $31,200 \mathrm{~g} \mathrm{~mol}^{-1}(\theta=2.2)$. Moreover, the ${ }^{1} \mathrm{H}-\mathrm{NMR}$ spectrum of 3 displays characteristic signals of both polymer blocks. For example, aromatic protons centred at $7.4 \mathrm{ppm}$ (a in Figure 2) and methylene protons adjacent to the oxygen in the phosphoester moiety (b in Figure 2) at 4.19 to $4.09 \mathrm{ppm}$ from block 2 as well as methylene protons adjacent to the ester group of the thiol-functional PDL moiety ( $\mathbf{f}$ in Figure 2 ) at 2.23 to $2.13 \mathrm{ppm}$. After precipitation, a coupling efficiency of around $20 \%$ was estimated. Although block coupling rates strongly depend on the structures and conditions, ${ }^{35,36}$ it is interesting to note that in the literature coupling efficiencies up to $90 \%$ are reported for DMPA thiol-ene reactions. ${ }^{37}$ Tentatively, the low efficiency achieved here might support the above discussed issues with endgroup fidelity of $\mathbf{2}$.

Table 1: Reaction conditions for the synthesis of poly(thioether-phosphoester).

\begin{tabular}{ccccc} 
Sample & Initiator $^{(\mathrm{a})}$ & Solvent $^{(\mathrm{b})}$ & $M_{n}\left(\mathrm{~g} \mathrm{~mol}^{-1}\right)^{(\mathrm{c})}$ & $\mathrm{Ð}_{\mathrm{M}}^{(\mathrm{c})}$ \\
\hline $\mathbf{2 . 1}$ & DMPA 1\% & Chloroform & 12700 & 2.4 \\
$\mathbf{2 . 2}$ & DMPA 1\% & Dichloromethane & 13200 & 2.3 \\
$\mathbf{2 . 3}$ & DMPA 5\% & Chloroform & 15650 & 2.3 \\
$\mathbf{2 . 4}$ & DMPA 5\% & Dichloromethane & 17200 & 2.2 \\
\hline
\end{tabular}

(a) The amount of initiator was calculated in wt.\% relative to the phenyl di(undec10-en-1-yl) phosphate used in the reactions. (b) In the solution reactions, solvents were used in a 1:1 mass ratio to phenyl di(undec-10-en-1-yl) phosphate. (c) Data from GPC analysis.

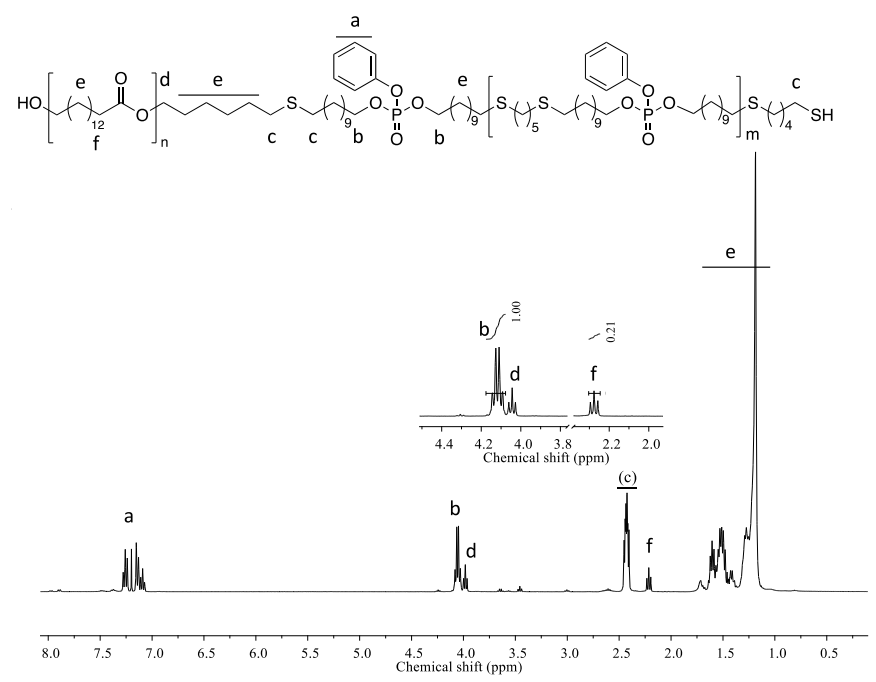

Fig. $2{ }^{1} \mathrm{H}-\mathrm{NMR}$ spectra (400 MHz) of poly( $\omega$-PDL- $b$-TEPE), produced by using a 1:2 molar ratio of thiol-functional PPDL to poly(thioether-phosphoester) and 5 wt.\% of DMPA under UV light at room temperature for 5 minutes. The inset shows the signals used to calculate the conjugation efficiency.
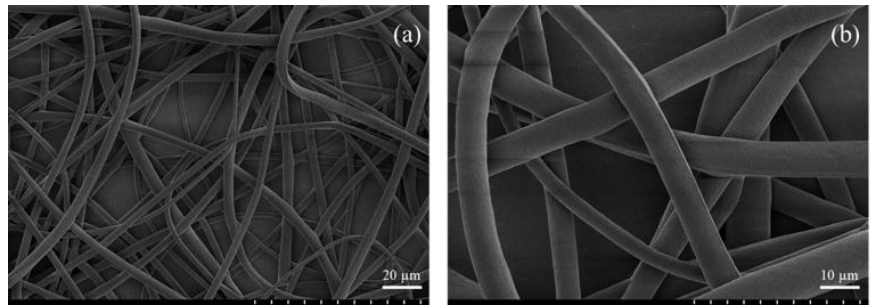

Fig. 3 SEM images of fibres obtained from a 1:1 mixture of poly( $\omega$-pentadecalactone) and poly $(\omega$-PDL- $b$-TEPE) using a voltage of $12 \mathrm{kV}, 10 \mathrm{~cm}$ of distance from the tip to collector, flow rate of $50 \mu \mathrm{L} \mathrm{min}{ }^{-1}$, concentration of $30 \mathrm{wt} . \%$ and a nozzle diameter of $1.02 \mathrm{~mm}$ (18 using G) ( $a$ and b). Image (b) is a magnification of image (a).

Attempts to electrospin copolymer $\mathbf{3}$ were unsuccessful. Success was only found when mixing $\mathbf{3}$ with equal mass with 
PPDL. As evident from SEM images, uniform fibres with diameters ranging from 5 to $15 \mu \mathrm{m}$ were obtained under optimised conditions (Figure 3). Generally, fibres where nontoxic against MC3T3 cells, a cell line of mouse calvaria, comparable to pure PPDL fibres (Figure S5, ESI). ${ }^{33,38}$ While the results signify the principle suitability of these polymers for biomedical application, the challenges in synthesis, characterisation and processing led us to explore a different polymer design where the phosphoester segments are conjugated as side groups.
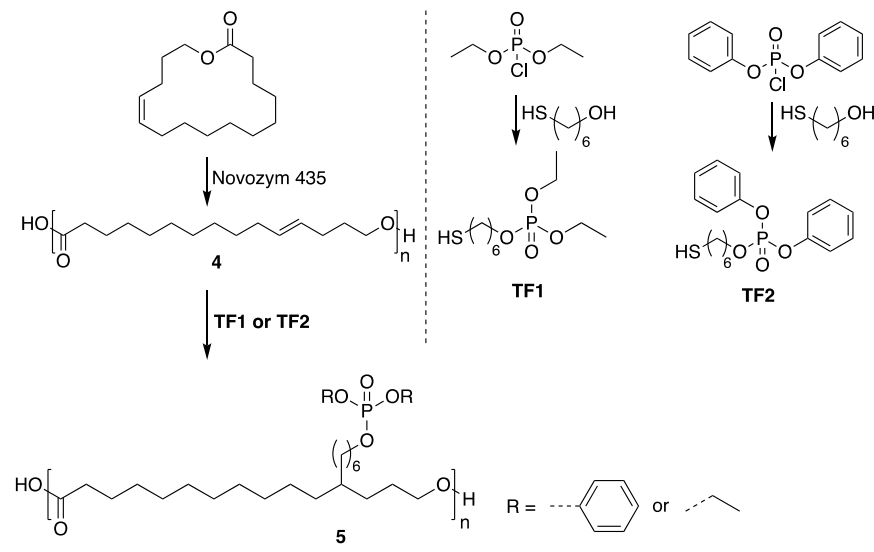

Scheme 2 Polymers with phosphoester side groups.

\section{Polymers with phosphoester side groups}

In this approach, thio-functional phosphoesters were conjugated to unsaturated poly(globalide) (PGI) 4 synthesised by lipase (Novozym 435) catalysed ring-opening polymerisation of globalide (Scheme 2) with an $M_{n}$ of $20,000 \mathrm{~g} \mathrm{~mol}^{-1}\left(\Theta_{\mathrm{M}}=3.5\right.$; Figure S6, ESI). The feasibility of thiol-ene modification and crosslinking of PGI double bonds was previously demonstrated. ${ }^{32,39-45}$ In order to study the structural influence of the phosphoester group on the properties of the final PGI conjugate, two different thiol-phosphoesters were used, denoted as TF1 and TF2 (Scheme 2). While TF1 is an ethyl phosphoester, TF2 is a phenyl phosphoster, both attached to a thiol group through a hexyl spacer. Synthesis of these compounds was adapted from a literature procedure and conducted by slow addition of the respective thiol and pyridine to the chlorophosphate in toluene over a period of $16 \mathrm{~h} .{ }^{46}$ The obtained products were purified by silica gel chromatography to obtain pure compounds TF1 and TF2 with yields $>60 \%$. The success of the syntheses as well as the purity of the compounds was assessed by ${ }^{1} \mathrm{H}-\mathrm{NMR}$ spectroscopy. Figure 4 depicts the example of TF1 displaying characteristic peaks for the methyl groups of the hexyl spacer ( $\mathbf{a}, \mathbf{b}$ and $\mathbf{e}$ ) and the phosphoester ethyl groups ( $\mathbf{a}$ and $\mathbf{d}$ ). Notably, the integrated peak area ratios of all signals are in agreement with the expected values, for example, those of the ethylene group adjacent to the thiol ( $b$ at $2.4 \mathrm{ppm}$ ) and the phosphoester ethylene groups ( $\mathrm{a}$ at $4.1 \mathrm{ppm}$ ). Similar ${ }^{1} \mathrm{H}-\mathrm{NMR}$ structural confirmation was obtained for TF2 (Figure S7, ESI).
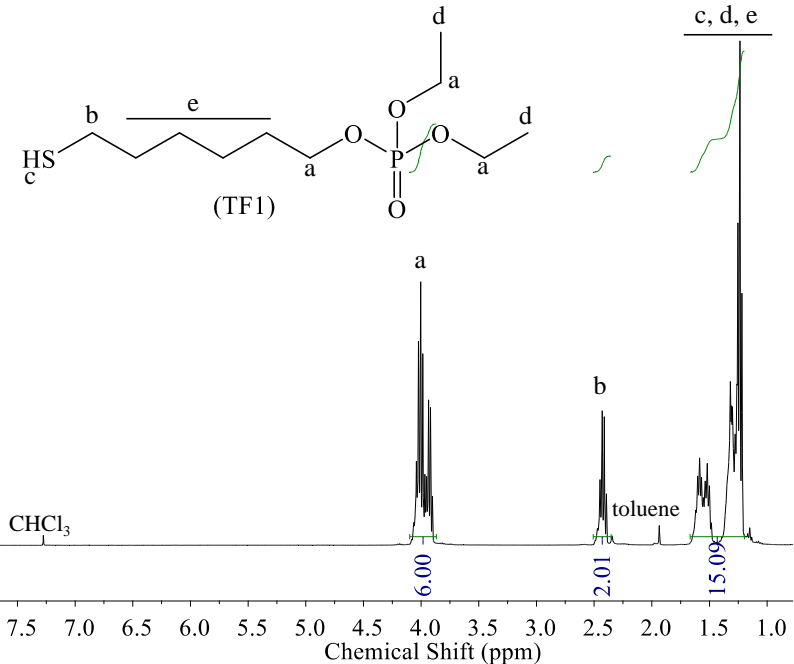

Fig. $4{ }^{1} \mathrm{H}-\mathrm{NMR}$ spectrum (400 MHz) of diethyl 6-mercapto-1-hexyl phosphate (TF1) in $\mathrm{CDCl}_{3}$.

The phosphoester thiols were subsequently reacted with the double bonds of the PGI in THF using AIBN as a thermal radical source. For both phosphoester thiols the theoretical thiol:ene ratio was varied from 0.5:1, 1:1 and 2:1, respectively, and for each of these ratios two molar concentrations of AIBN were applied (Table 2). First qualitative evidence for the successful reaction was obtained from FTIR spectra of the isolated polymers displaying characteristic phosphoester bands (Figure S8, ESI). The double bond conversion was quantified by comparing the ${ }^{1} \mathrm{H}-\mathrm{NMR}$ integrated peak areas corresponding to the PGI double bond protons at $5.4 \mathrm{ppm}$ and PGI methylene group adjacent to hydroxyl terminal group at $4.1 \mathrm{ppm}$ in case of polymers modified with TF2 (Figure S9, ESI). When TF1 was used, ethyl peaks of the phosphoester overlapped with the ethyl peak of the PGI, so that in this case the conversion was estimated comparing PGI double bond protons at $5.4 \mathrm{ppm}\left(\mathbf{a}, \mathbf{a}^{\prime}\right.$ in Figure 5a) and ethyl groups adjacent to the carbonyl group at $2.3 \mathrm{ppm}$ (c in Figure 5a). Figure 5 depicts the example of the PGI before and after reaction with TF1 (thiol:ene ratio 2:1, 5\% AIBN, Table 2 entry $6 \mathrm{M} 6$ ). The reduction in double bond signals after thiol addition and the appearance of TF1 peaks in the spectrum of the functionalised polymer is clearly visible with peaks corresponding to the ethyl group adjacent to oxygen at 4.13$4.06 \mathrm{ppm}$ ( $\mathrm{A}-\mathrm{C}$ in Figure $5 \mathrm{~b}$ ) and methyl groups adjacent to the sulphur atom at 2.47-2.42 ppm ( $D$ in Figure $5 \mathrm{~b}$ ). For this particular example, a double bond conversion of $84 \%$ was calculated. 
Table 2: Poly(globalide) functionalisation via thiol-ene reactions using TF1 and TF2.

\begin{tabular}{ccccccc} 
Entry & Thiol & $\begin{array}{c}\text { AlBN } \\
{[\mathrm{mol} \%]}\end{array}$ & $\begin{array}{c}\text { Molar ratio } \\
\text { thiol:ene }\end{array}$ & $\begin{array}{c}\text { DB conv. } \\
(\%)\end{array}$ & $\begin{array}{c}T_{m}{ }^{(\mathrm{b})} \\
\left({ }^{\circ} \mathrm{C}\right)\end{array}$ & $\begin{array}{c}\Delta H_{m}{ }^{(\mathrm{b})} \\
\left(\mathrm{Jg}^{-1}\right)\end{array}$ \\
\hline PG1 & - & - & - & - & 41.0 & 160.4 \\
$6 \mathrm{M} 1$ & TF1 & 1 & $0.5: 1$ & 14 & 32.8 & 77.1 \\
$6 \mathrm{M} 2$ & TF1 & 5 & $0.5: 1$ & 17 & 29.0 & 72.0 \\
$6 \mathrm{M} 3$ & TF1 & 1 & $1: 1$ & 20 & 33.11 & 73.0 \\
$6 \mathrm{M} 4$ & TF1 & 5 & $1: 1$ & 36 & - & - \\
$6 \mathrm{M} 5$ & TF1 & 1 & $2: 1$ & 45 & - & - \\
$6 \mathrm{M} 6$ & TF1 & 5 & $2: 1$ & 84 & - & - \\
Ph3 & TF2 & 1 & $1: 1$ & 4 & 28.3 & 112.3 \\
Ph4 & TF2 & 5 & $1: 1$ & 7 & 15.8 & 93.5 \\
Ph5 & TF2 & 1 & $2: 1$ & 17 & 16.1 & 37.5 \\
Ph6 & TF2 & 5 & $2: 1$ & 28 & & - \\
\hline
\end{tabular}

aDouble bond conversion \% determined by ${ }^{1} \mathrm{H}-\mathrm{NMR}$. ${ }^{\mathrm{b}}$ Melting point determined by the second heating curve from DSC. 'Enthalpy of fusion determined by integration of the second heating curve from DSC.

(a)<smiles>CCCCCCCCC=CCCCCCOP</smiles>

(b)

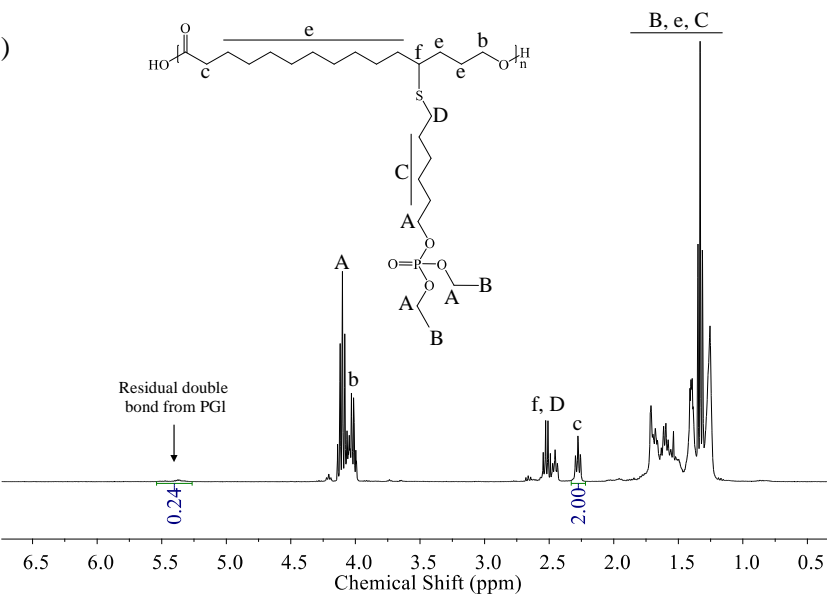

Fig. $5^{1} \mathrm{H}-\mathrm{NMR}$ spectra $\left(400 \mathrm{MHz}\right.$ ) in $\mathrm{CDCl}_{3}$ showing the characteristic peaks of (a) PGI and (b) PGI-TF1 (entry 6M6 in Table 2).

Changing the reactant ratios, the degree of TF1 functionalisation could be increased from 14 to $84 \%$ (Table 2). PGI modification with TF2 resulted in a significantly lower double bond conversion with a maximum of $28 \%$ when a molar ratio thiol:ene of 2:1 was used at 5 mol\% AIBN concentration. While TF2 also contains a hexyl spacer, it is speculated that the presence of the bulky benzyl rings could cause additional steric hindrance thus reducing the reaction efficiency. As a general trend, a higher coupling yield was obtained by increasing the AIBN concentration and thiol:ene ratio. This is in agreement with previous studies of PGI functionalisation with $\mathrm{N}$ acetylcysteamine, for which double bond conversions ranging from 17 to $95 \%$ using molar thiol:ene ratios of 0.4:0.6 and 6.6:0.6 were obtained. ${ }^{40}$

The thermal properties of PGI before and after modification were accessed by differential scanning calorimetry (DSC) and results are listed in Table 2 . PGI is a semi-crystalline polymer with a melting temperature $\left(T_{m}\right)$ of $40-48{ }^{\circ} \mathrm{C} .{ }^{38}$ DSC curves obtained for each polymer showed that the melting temperature and the enthalpy of fusion $\left(\Delta H_{m}\right)$ were dependent on the double bond conversion. The DSC melting temperature curves and the physical appearance of PGI-TF1 polymers are depicted in Figure 6. It is possible to see the decrease in $T_{m}$ after TF1 addition for the polymers up about 20\% TF1 functionalisation in the DSC plots (6M1-6M3). All polymers with functionalisation degrees $>36 \%$ (6M4 and higher) were fully amorphous and liquid at room temperature. The transition from a white solid material to viscous and transparent amorphous polymers with higher degrees of TF1 functionalisation is also apparent from the image in Figure 6. A similar trend was observed for the TF2 functionalised PGI (Figure S10, ESI).
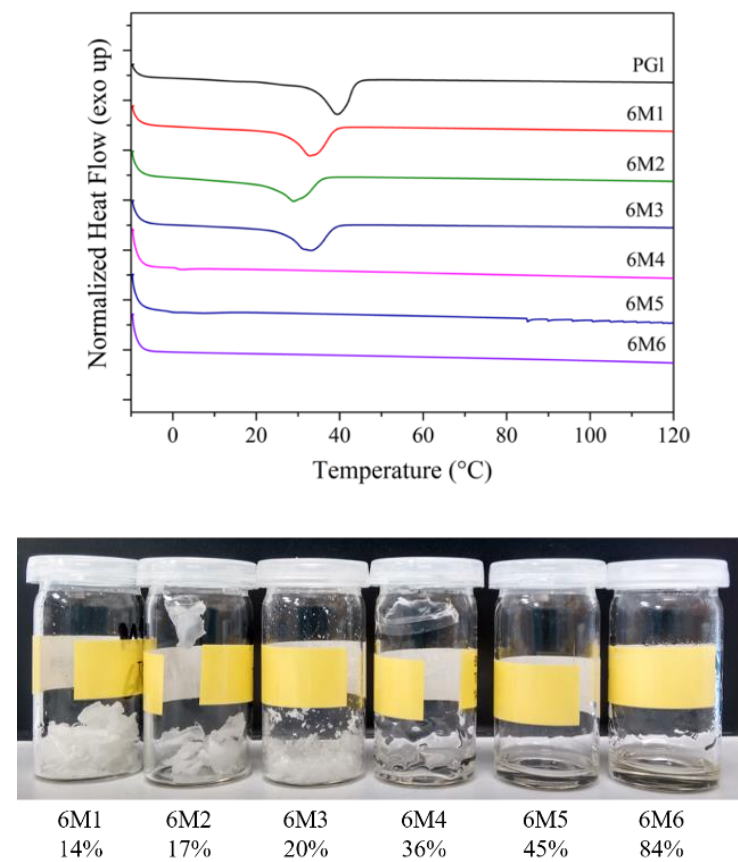

Fig. 6 Differential scanning calorimetry (DSC) thermograms (second heating curve) before and after post-polymerisation modification of PGI with TF1 (top). Physical appearance of $\mathrm{PGI}$ after post-polymerisation modification with TF1 at room temperature (bottom).

In order to assess whether phosphoester functional PGI could be electrospun into defined fibre meshes, sample $6 \mathrm{M} 1$, with a 14\% TF1 functionalisation was selected for trials. This choice was guided by the fact that this sample is solid at room temperature, which is required for a successful spinning 
process. Homogeneous fibres were obtained at a tip to collector distance of $15 \mathrm{~cm}$, a flow rate of $100 \mu \mathrm{L} / \mathrm{min}$, a polymer concentration of $30 \%$, a nozzle diameter of $1.02 \mathrm{~mm}$ (18 using G) and a voltage of $12 \mathrm{kV}$ for $\mathrm{PGI}$ and $8 \mathrm{kV}$ for $6 \mathrm{M} 1$, respectively. SEM micrographs (Figure 7) confirm that fibres meshes obtained under these conditions display well-separated individual fibres with a largely homogeneous morphology and a diameter of 8-11 $\mu \mathrm{m}$. Closer inspection of the SEM images of the fibres obtained from the phosphoester functional PGI - 6M1 reveals thicker sections as well as some surface roughness as compared to the PGI control fibres. This is ascribed to solvent effects and possibly to the lower melting point of the materials.
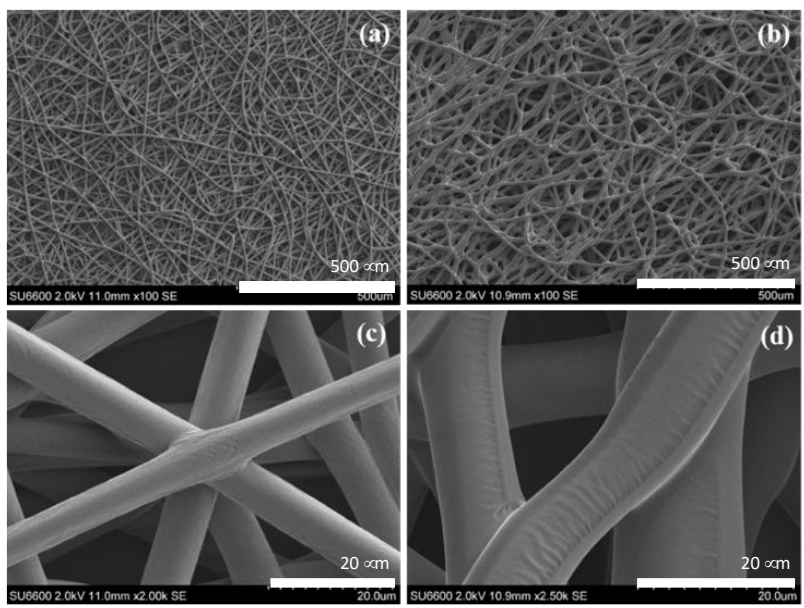

Fig. 7 SEM images of electrospun fibres from PGI - $500 \mu \mathrm{m}$ (a), 6M1 - $500 \mu \mathrm{m}$ (b), PGI $20 \mu \mathrm{m}$ (c) and $6 \mathrm{M} 1-20 \mu \mathrm{m}$ (d). Tip to collector distance $15 \mathrm{~cm}$, flow rate of $100 \mu \mathrm{L} / \mathrm{min}$ polymer concentration $30 \%$, nozzle diameter $1.02 \mathrm{~mm}$ and voltage of $12 \mathrm{kV}$ for PGI and $8 \mathrm{kV}$ for $6 \mathrm{M} 1$.

The biocompatability of the TF1-PGI fibres from $6 \mathrm{M} 1$ and nonmodified PGI was accessed using human dermal fibroblasts. Fibroblasts were seeded at a density of 2000 cells/disc and cell metabolic activity was measured after 7 days of culture (Figure 8). An alamar blue assay revealed a metabolic activity of $0.82 \pm 0.10$ (mean \pm standard error of the mean) for $6 \mathrm{M} 1$ at day 7 , when normalized to PGI controls. There was no statistic difference between the samples $(p=0.45)$. This result suggests that $6 \mathrm{M} 1$ and $\mathrm{PGI}$ similarly sustained human dermal fibroblasts growth over a period of 7 days in culture. Live/dead staining followed by confocal microscopy imaging was performed to qualitatively observe cell viability after 7 days of culture (Figure 8). For both polymers, the majority of cells stained green (live), with a small percentage stained red (dead cells), corroborating the alamar blue findings. Thus, both polymers successfully sustained human dermal fibroblasts culture over a period of 7 days and the elongated morphology of the cells in the 6M1 polymer indicates a better attachment than in non-modified $\mathrm{PGI}$, although more detailed studies are required to monitor the cell behaviour.
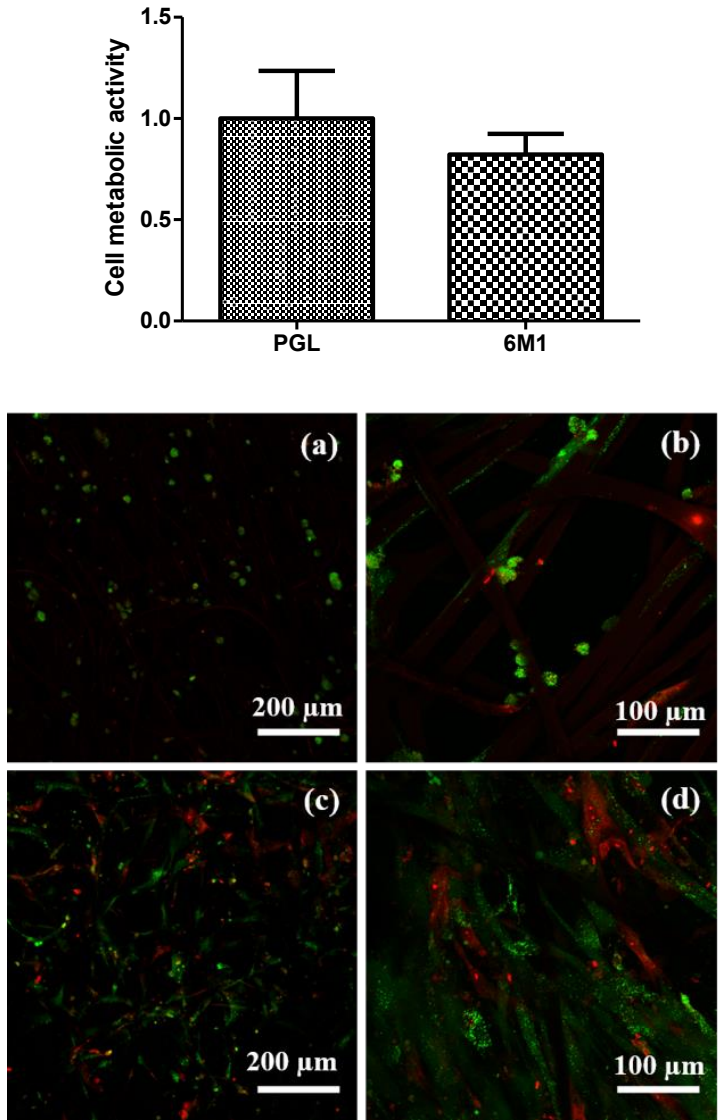

Fig. 8 Metabolic activity of cells seeded on PGI and 6M1 fibres after 7 days of culture. Data is reported as mean \pm standard error of the mean (top). There was no statistic significant difference between the samples $(p=0.45)$. Live/dead images of cells at day 7 in PGI $(a, b)$ and $6 \mathrm{M} 1(\mathrm{c}, \mathrm{d})$. Live cells are stained in green (calcein-AM) and dead cells in red (ethidium homidimer-1) (bottom).

\section{Conclusions}

We have presented two novel polymer motives with phosphoester groups in the main and side chain utilising thiolene chemistry. While the successful synthesis of both structural motives was demonstrated, the side chain functionalisation of unsaturated poly(globalide) with phophoesters proved synthetically more feasible. The resulting polymers transitioned from solid semicrystaline to liquid amorphous with increasing degree of phosphoester conjugation. Electrospun fibres from polymers with $14 \%$ phosphoester conjugation allowed attachment and survival of human dermal fibroblasts. However, the amorphous appearance of samples with higher phosphoester content rendered them unsuitable for electrospinning. Nevertheless, these polymers present an interesting new class of easily accessible biocompatible materials and open possibilities to design novel biomaterials for example through crosslinking by utilising the remaining poly(globalide) double bonds.

\section{Conflicts of interest}

There are no conflicts to declare. 


\section{Acknowledgements}

R.J.F.C.A. acknowledges support from Science Foundation Ireland (SFI), European Regional Development Fund (Grant Number 13/RC/2073). V.C., D.O., P.H.H.A. and C.S. received funding from CAPES (Coordenação de Aperfeiçoamento de Pessoal de Nível Superior) and CNPq (Conselho Nacional de

1 F. J. O’Brien, Mater. Today, 2011, 14, 88.

2 H. Ye, K. Zhang, D. Kai, Z. Li and X. J. Loh, Chem. Soc. Rev., 2018, 47, 4545 .

3 S. Ahadian and A. Khademhosseini, Regen. Biomater., 2018, 5 , 125.

4 Z. Sheikh, S. Najeeb, Z. Khurshid, V. Verma, H. Rashid and M. Glogauer, Materials, 2015, 8, 5744 .

5 D. P. Walsh, R. M. Raftery, I. M. Castaño, R. Murphy, B. Cavanagh, A. Heise, F. J. O'Brien and S. Cryan, J. Control. Release, 2019, 304, 191.

6 W. D. Chan, H. Perinpanayagam, H. A. Goldberg, G.K. Hunter, S. J. Dixon, G.C. Santos and A. S. Rizkalla, J. Can. Dent. Assoc., 2009, 75, 373.

7 W. Chen, H. Yang, R. Wang, R. Cheng, F. Meng, W. Wei and Z. Zhong, Macromolecules, 2010, 43, 201.

8 8T.J. Sill and H. A. von Recum, Biomaterials, 2008, 29, 1989.

9 S. Jian, J. Zhu, S. Jiang, S. Chen, H. Fang, Y. Song, G. Duan, Y. Zhang and H. Hou. RSC Adv., 2018, 8, 4794.

10 S. K. Tiwari and S. S. Venkatraman, Mater. Sci. Eng. C., 2012, 32, 1037.

11 G. Duan, A. R. Bagheri, S. Jiang, J. Golenser, S. Agarwal and A. Greiner, Biomacromolecules, 2017, 18, 3215.

12 I. Jun, H. S. Han, J. R. Edwards and H. Jeon, Int. J. Mol. Sci., 2018, 19, 745.

13 D.I. Braghirolli, D. Steffens and P. Pranke, Drug Discov. Today, 2014, 19, 743.

14 K.N. Bauer, H. T. Tee, M. M. Velencoso and F. R. Wurm, Prog. Polym. Sci., 2017, 73, 61.

15 G. Settanni, J. Zhou, T. Suo, S. Schöttler, K. Landfester, F. Schmid and V. Mailänder, Nanoscale, 2017, 9, 2138.

16 Z. E. Yilmaz and C. Jérôme, Macromol. Biosci., 2016, 16, 1745.

17 Z. Zhao, J. Wang, H. Q. Mao and K. W. Leong, Adv. Drug Deliv. Rev., 2003, 55, 483

18 X. Xu, H. Yu, S. Gao, H. Q. Mao, K. W. Leong and S. Wang, Biomaterials, 2002, 23, 3765.

19 B. Clément, D. G. M. Molin, C. Jérôme and P. Lecomte, J. Polym. Sci. Part A Polym. Chem., 2015, 53, 2642.

20 B. M. Watson, F. K. Kasper and A. G. Mikos, Biomed. Mater. 2014, 9, 265.

21 J. Z. Du, D. P. Chen, Y. C. Wang, C. S. Xiao, Y. J. Lu, J. Wang and G. Z. Zhang, Biomacromolecules, 2006, 7, 1898.

22 W. Zhu, S. Sun, N. Xu and Z. Shen, J. Polym. Sci. Part A Polym. Chem., 2011, 49, 4987

23 Y. C. Wang, L. Y. Tang, T. M. Sun, C. H. Li, M. H. Xiong and J. Wang, Biomacromolecules, 2008, 9, 388.

24 W. J. Song, J. Z. Du, N. J. Liu, S. Dou, J. Cheng and J. Wang, Macromolecules, 2008, 41, 6935.
Desenvolvimento Científico e Tecnológico). The authors would like to thank Brenton Cavanagh from RCSI Cellular and Molecular Imaging Core for his contributions with live/dead experiment imaging acquisition.

\section{Notes and references}

25 J. Wen, G. J. A. Kim and K. W. Leong, J. Control. Release, 2003, 92, 39 .

26 X. Z. Yang, T. M. Sun, S. Dou, J. Wu, Y. C. Wang and J. Wang, Biomacromolecules, 2009, 10, 2213.

27 H. Shao, M. Zhang, J. He and P. Ni, Polymer, 2012, 53, 2854.

28 J. Wen, G. J. A. Kim and K. W. Leong, J. Control. Release, 2003 92, 39 .

29 J. Z. Du, D. P. Chen, Y. C. Wang, C. S. Xiao, Y. J. Lu, J. Wang and G. Z. Zhang, Biomacromolecules, 2006, 7, 1898.

30 M. Takwa, N. Simpson, E. Malmström, K. Hult, M. Martinelle, Macromol. Rapid Commun., 2006, 27, 1932.

31 F. Marsico, M. Wagner, K. Landfester, and F. R. Wurm, Macromolecules, 2012, 45, 8511.

32 F. C. S. de Oliveira, D. Olvera, M. J. Sawkins, S. A. Cryan, S. D. Kimmins, T. E. da Silva, D. J. Kelly, G.P. Duffy, C. Kearney and A. Heise, Biomacromolecules, 2017, 18, 4292.

33 M. L. Focarete, C. Gualandi, M. Scandola, M. Govoni, E. Giordano, L. Foroni, S. Valente, G. Pasquinelli, W. Gao and R. A. Gross, J. Biomater. Sci. Polym. Ed., 2010, 21, 1283.

34 M. Steinmann, F. Marsico and F. R. Wurm, J. Polym. Res. 2015 , 22, 143.

35 S. P. S. Koo, M. M. Stamenovic, R. A. Prasath, A. J. Inglis, F. E. DuPrez, C. Barner-Kowollik, W. Camp Van and T. Junkers, J. Polym. Sci. Part A Polym. Chem., 2010, 48, 1699.

36 B. Colak, J. C. S. Da Silva, T. A. Soares and J. E. Gautrot Bioconjug. Chem., 2016, 27, 2111.

37 B. D. Fairbanks, D. M. Love, C. N. Bowman, Macromol. Chem Phys., 2017, 218, 1.

38 I. Van Der Meulen, M. De Geus, H. Antheunis, R. Deumens, E. Joosten, C. E. Koning and A. Heise, Biomacromolecules 2008, 9, 3404.

39 J. A. Wilson, Z. Ates, R. L. Pflughaupt, A. Dove and A. Heise, Prog. Polym. Sci., 2019, 91, 29.

40 Z. Ates, D. Thornton and A. Heise, Polym. Chem., 2011, 2, 309

41 Z. Ates and A. Heise, Polym. Chem., 2014, 5, 2936.

42 Z. Ates, F. Audouin, A. Harrington, B. O'Connor and A. Heise, Macromol. Biosci., 2014, 14, 1600.

43 C. L. Savin, C. Peptu, Z. Kroneková, M. Sedlacík, M. Mrlik, V. Sasinková, C. A. Peptu, M. Popa, and J. Mosnácek, Biomacromolecules, 2018, 19, 3331.

44 C. Guindani, P. Dozoretz, P. H. H. Araújo, S. R. S. Ferreira, and D. De Oliveira, Mater. Sci. Eng. C, 2019, 94, 477.

45 I. Van Der Meulen, Y. Li, R. Deumens, E. J. Joosten, C. E. Koning and A. Heise, Biomacromolecules, 2011, 12, 837.

46 G. Clouet and M. Knipper, Makromol. Chem., 1987, 188, 2597. 